Vol. 1, No. 2, 2016

\title{
MULTIAGENT CONTROL AND PREDICTIVE DIAGNOSTICS OF DISTRIBUTED IRON ORE ENRICHMENT SYSTEM BASED ON CPS
}

\author{
Volodymyr Morkun, Oleksandr Savytskyi, Maxym Tymoshenko \\ SIHE “Kryvyi Rih National University”, 11, Vitaliy Matusevych str., Kryvyi Rih, 50027, Ukraine \\ Authore-mail:musicvano@gmail.com
}

Submitted on 01.10.2016

(C) Morkun V., Savitskyi O., Tymoshenko M., 2016

\begin{abstract}
The paper presents a description of a distributed control system of processing complex, consisting of three stages with a predictive diagnosis of sensors and actuators. Innovative methods of multi-agent control re focused on as one of the CPS concepts to improve the relation between different stages of enrichment equipment and their coordination.
\end{abstract}

Index Terms: Control Systems, Cyber-Physical Systems, Enrichment, Industry 4.0, Multiagent Control, Predictive Diagnostics

\section{INTRODUCTION}

Given the trends of modern global market orientation the main goal of production is to reduce the cost of the product. This goal is achieved through a comprehensive optimization of production processes with the help of modern technologies. It is improving the quality of industrial automation processes which is the main way to solve the issue of energy efficiency.

The enrichment complex includes many technological units which carry out different operations and are different in design, and therefore require the use of different approaches in the construction and implementation of control systems. In addition, enrichment devices are directly interrelated and affect each other; they require the use of many measuring instruments recording the values of different physical nature, which increases the required computational capacity [1-4].

\section{PROSPECTS OF MULTIAGENT CONTROL FOR DEVELOPMENT OF IRON ORE ENRICHMENT CONTROL SYSTEM}

The mentioned difficulties can be avoided by using a distributed control. Considering the complex of iron ore enrichment as one big distributed system of decentralized mechanisms it is possible to synthesize the control system of every mechanism of each stage separately, which are in constant relation. This approach enables to increase performance and reduce the load on the overall system, and reduce requirements for computational capacity of the executive system .

However, the distributed control has its own shortcomings, the most important of which is the existence of a certain "command center". Although the mechanisms work independently in distributed control, yet there is a center which handles all the data needed to adjust interaction between controlled mechanisms and concentrates considerable computational resources. In case of the control center failure, system objects will not be able to interact.

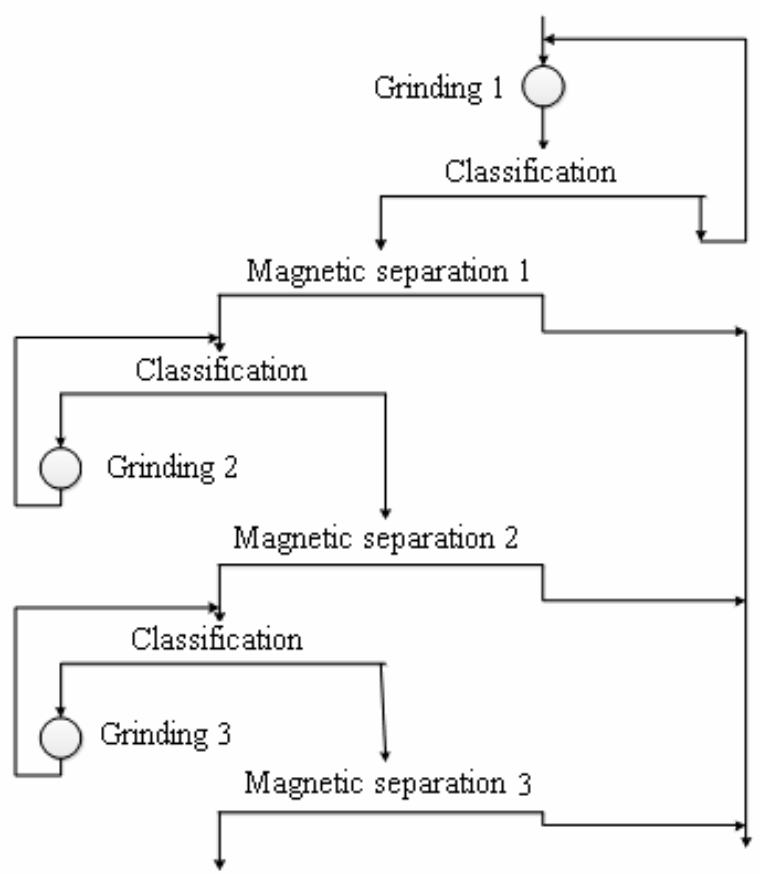

Fig. 1. Three-stage technological scheme of iron ore enrichment process

Multiagent control (MAC) allows to avoid these shortcomings. Multiagent control is one of the leading concepts of fourth scientific and technological revolution, and informational (Industry 4.0). It implies a complete decentralization of control, lack of some main system and the free operation of each technological mechanisms control system (agent) independently. However, the agents harmoniously interact and exchange information with each other. The main difference of the approach, based on the principles of collective multiagent control, is relatively low design complexity of implementing its algorithms which allows quick taking if not the best, then close to them decisions in condition of a dynamically changeable situation [5-7]. 
Fig. 1 and 2 show the technological process diagram of three-stage crushing of iron ore and present links between technological units as agents between the MAC. Communication between agents in Fig. 2 is wireless, as laying cables along considerable distances in heavy production conditions as well as ensuring their reliable operation is a very complicated task. Only in the early stages, which are closest to the control room, there is also communication protocol for industrial Ethernet, which provides a high speed data transfer. Each technological mechanism is put in line with its own agent having its own control system (Fig. 2). However, in the first stage the classification is fulfilled not with the help of hydrocyclone but using the spiral classifier. Since the latter is not a very complex mechanism and does not require significant management costs, together with the magnetic separator in the first stage they can be considered as one agent.

Fig. 3 is a more advanced circuit shown in Fig. 2 and presents a design of multiagent control of three stages enrichment considering communication between them and the transfer of information signals from the sensors to the PLC. In the first stage iron ore comes from the feeder to the mill. Regulation of the ore amount is carried out by feeder drive control, which is exercised by the actuator feeder (Af). After the first and second stages of grinding between stages intermediate density measurements are conducted using densitometer $(\rho)$. Except the density of the final product after the third stage much more required parameters are measured such as particle size of the grinded material using granulometer (GM), the content of useful component (magnetic iron), fixed by sensor indicated in the figure as $(\%)$, and productivity on the water and for the whole pulp (consumption meters Qw and Qp respectively). Each stage has its own PLC, which collects the data and sends them to a PC for processing. Based on the data algorithm calculates the control action and submits it to the actuators (A1, A2 and A3), which, in turn, regulate the supply of additional water to the mill. Considering that the hydrocyclone sump is kept optimal level, we can control not only the supply of additional water, but also control the supply of pulp. Therefore, there are formed three more control actions which are applied to hydrocyclone pumps (P1, P2 and P3). There is control of separators based on mechanisms Rs. Simultaneously visualization is made in SCADA-based system on the basis of data calculated in the PC. Among other things the system carries out diagnostics of sensors and actuators. Knowing their status and the current operating mode you can say if the equipment is working correctly or not and, thus, prevent accidents. For example, if values of the level or productivity sensor sharply changed to larger values, this means that it is faulty, because such an abrupt change is a physically impossible value. The diagnosis system increases the durability of the system and the accuracy of the measured readings.

Earlier [8] there was considered an enrichment process control system based on application of fuzzy logic. Let us view separately hydrocyclone separation processes in the second stage.

On condition of hydrocyclone control system effective work qualitative and quantitative parameters of flows are optimized, decreasing the overall cost of concentrate. Hydrocyclone regulation is aimed at achieving two goals: quantitative (productivity for the finished product) and quality (effectiveness of separation and particle size distribution). Hydrocyclone should not be considered separately from the sump associated with the previous stage grinding, which also increases the number of options under consideration in driving a technological mechanism [9-12]. Automated control of complex object should be created based on algorithms that do not require detailed background information about the control object.

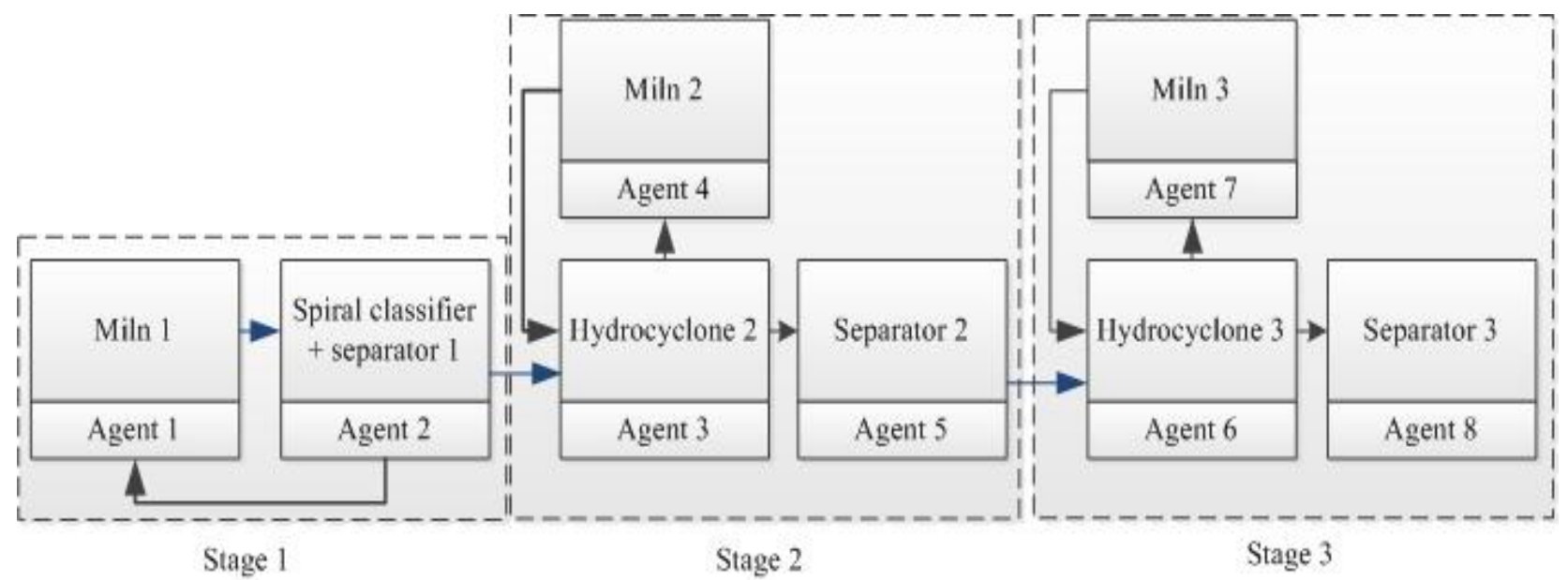

Fig. 2. Presentation of relations between control agents 


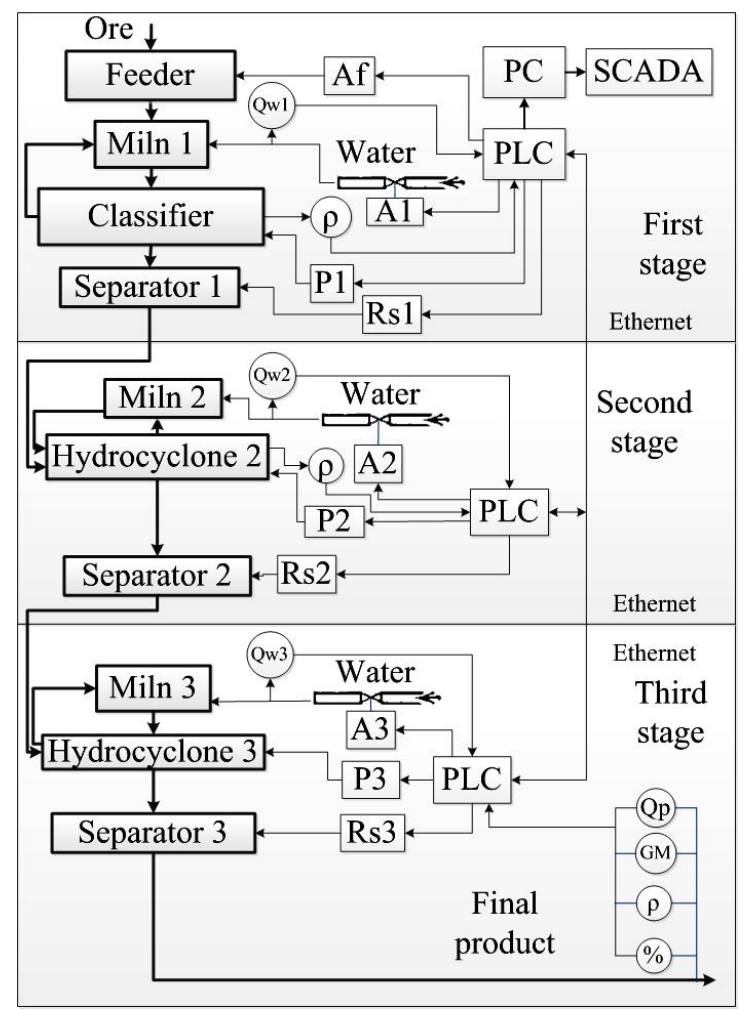

Fig. 3. Multiagent self-diagnosed control system of three-stage enrichment taking into account connections between agents

This is the difficulty of drawing a mathematical model of hydrocyclone that entails the use of modern intelligent means, including means of fuzzy logic.

In technological schemes of the enrichment complex, in the second stage several hydrocyclones are usually used (each with its own drive). We will assume that the other hydrocyclones are fully loaded according to the project standards and productivity fluctuations of stage occur only within one hydrocyclone.

In general, the agent is represented as a tuple [15]:

$$
\mathrm{A}=<\mathrm{G}, \mathrm{S}, \mathrm{A}, \theta, \varphi>,
$$

where $\mathrm{G}$ - target function, $\mathrm{S}=\left\{\mathrm{s}_{1}, \mathrm{~s}_{2, \ldots} \mathrm{s}_{\mathrm{n}}\right\}$ - set of state parameters, $A=\left\{a_{1}, a_{2, \ldots} a_{n}\right\}-$ set of actions, $\theta-$ knowledge base, $\varphi$ - operator.

The control core is maintaining the productivity value of underflow and overflow at a certain level. Therefore, the second stage hydrocyclone target function $\mathrm{G}$ will be a criterion

$$
\mathrm{K}=\mathrm{Q}_{\mathrm{of}} / \mathrm{Q}_{\mathrm{uf}} ; \rho_{\text {of }} \leq \rho_{\text {of. } n} ; \rho_{\mathrm{uf}} \geq \rho_{\text {uf.n }}
$$

where $\mathrm{Q}_{\mathrm{of}}, \mathrm{Q}_{\mathrm{uf}}$-productivities of overflow and underflow accordingly; $\rho_{\text {of }}, \rho_{\text {of.n }}$ - current and limited (the maximum allowable) density of underflow; $\rho_{\text {uf }}, \rho_{\text {uf.n }}-$ current and limited (the minimum allowable) density of overflow.

State parameters are the density of underflow and overflow, productivity of underflow and overflow, level of pulp in the sump and pressure generated by the hydrocyclones pump. A state of sensors and actuators to diagnose system are also included. A set of actions will consist of regulatory influences, such as hydrocyclone motor pump speed rotation control as well as adding technological water in the sump. The knowledge basis contains in itself the previous experience of control and routing of ore varieties to adapt to certain types of iron ore.

In the adaptive approach to building fuzzy control systems blocks of logic fuzzy inference configuration is carried out not only in the design process, but also during the normal operation of the system in parallel with the object control. Adaptive systems allow a better control of complex, as in our case, non-stationary objects compared to conventional systems.

Fig. 4 shows the agent control principle in this case. Error of difference between input and output from the control object, that is incoming on the negative feedback, is provided to the regulator. In Fig. 4, the block "control object" also includes an actuator. The block "controlling object" contains fuzzy network which teaches the regulator based on the received signals. Based on signals of regulator's input and control object's output fuzzy network with predetermined base of rules teaches the regulator, changing its time constants and gains.

Fig. 5 shows the control of the first stage of enrichment, showed if Fig. 3. PLC 1 receives signals from the sensors of density and productivity and on the basis of the received data fuzzy network trains regulators controlling the actuators of the feeder, classifier, wet magnetic separator and water supply to the mill. Since the essence of the agents is their autonomy with supported communication, it is necessary to implement communication between them. Within one stage this exchange may be carried out by software in the PLC. For the exchange of information between the stages data is transferred by the PLC of each stage.

Fig. 6, 7 and 8 show algorithms of PLC's functioning, according to Fig. 5. Due to the fact that in the third stage there are more measured and controlled parameters, the PLC's algorithm for the third stage is more difficult. All three algorithms are working parallelly. They start working at the same time and in the process exchange data, as it is shown in Fig. 5.

Fig. 9 shows a parallel functioning of algorithms. If during the operation of a stage some important parameter of technological mechanism or processed product has changed, a condition arises - is it necessary to transfer parameter $\left(\mathrm{P}_{\mathrm{i}}\right)$ to the neighboring agent? If there is no need in transferring any parameters to agents of other stages, the algorithm simply continues to operate normally.

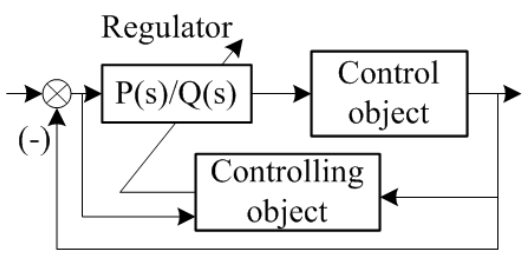

Fig. 4. Agent control principle 


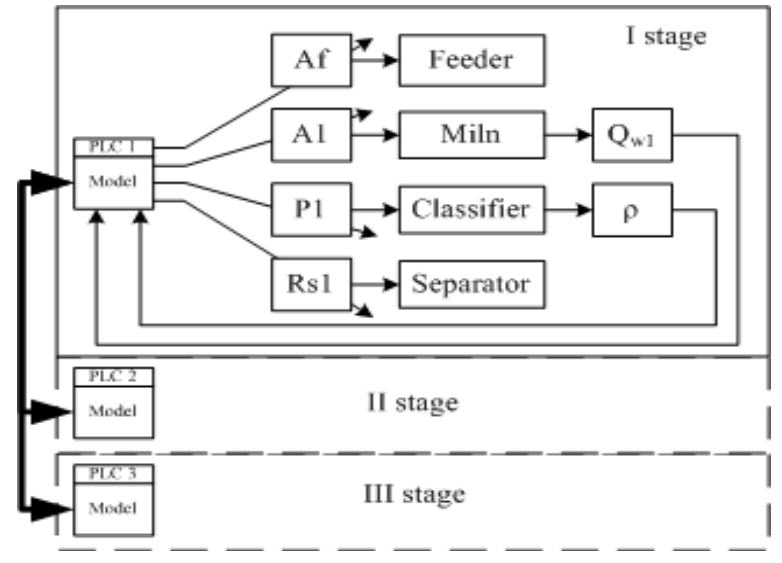

Fig. 5. Control of agents in first stage of enrichment

Control system of hydrocyclone, as the agent is shown in Fig. 10. It is considered the second stage of enrichment's hydrocyclone as a single control agent, which is also associated with other mechanisms of the second stage, and mechanisms of prior and subsequent stages.

This system can also be implemented taking into account self-diagnosing circuit. It involves selfdiagnostic of measurement devices and actuators. In this case, these are the motor of hydrocyclone's pump, sensors of densities and productivities of overflow and underflow measuring, sensor of pulp level in the sump, the water flows to the sump sensor and the valve. Due to the large number of sensors, measurement of process parameters can be redundant, but it also makes it possible to diagnose the sensors or actuators failure.

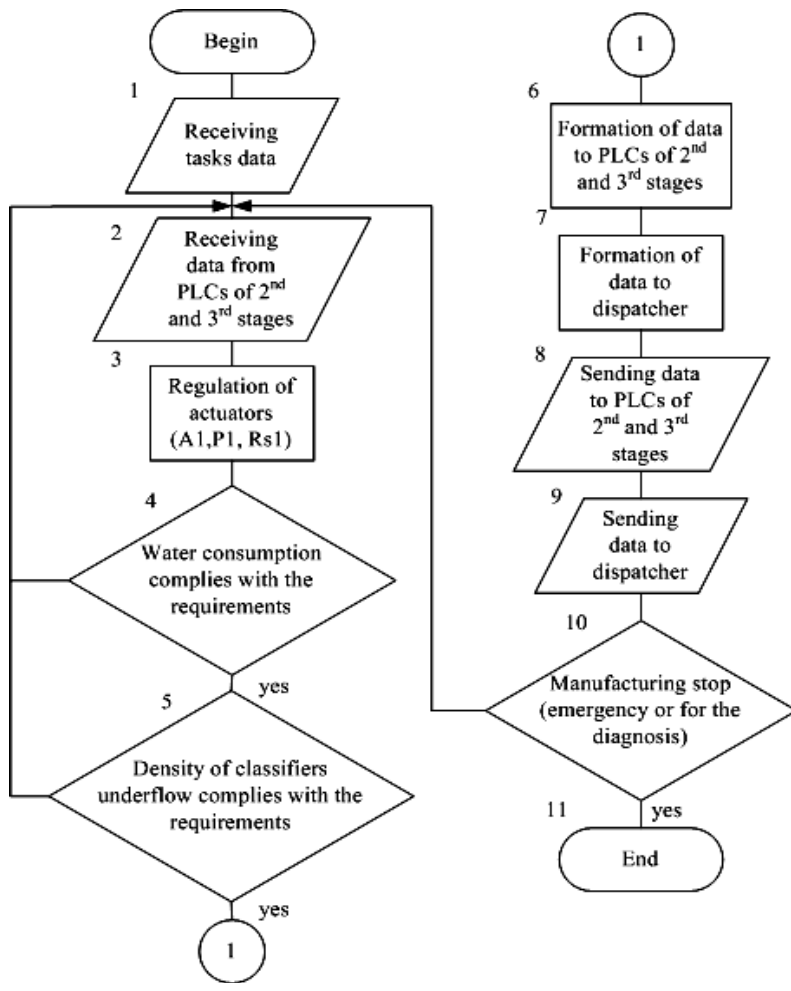

Fig. 6. The operation algorithm of PLC in the first stage of iron ore enrichment

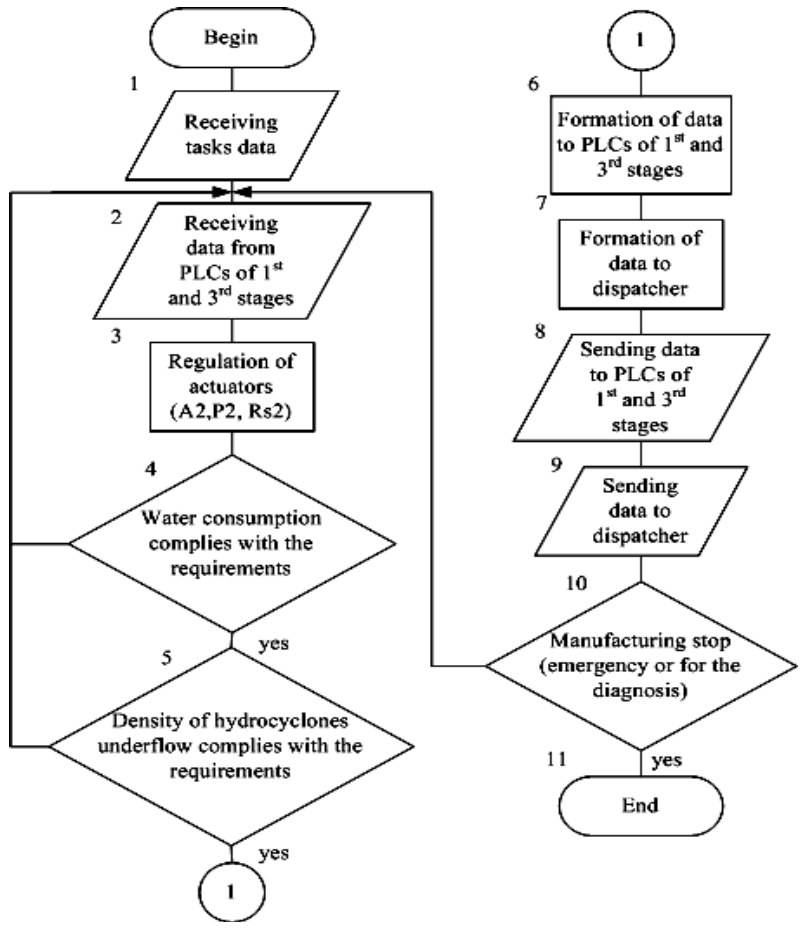

Fig. 7. The operation algorithm of PLC in the second stage of iron ore enrichment

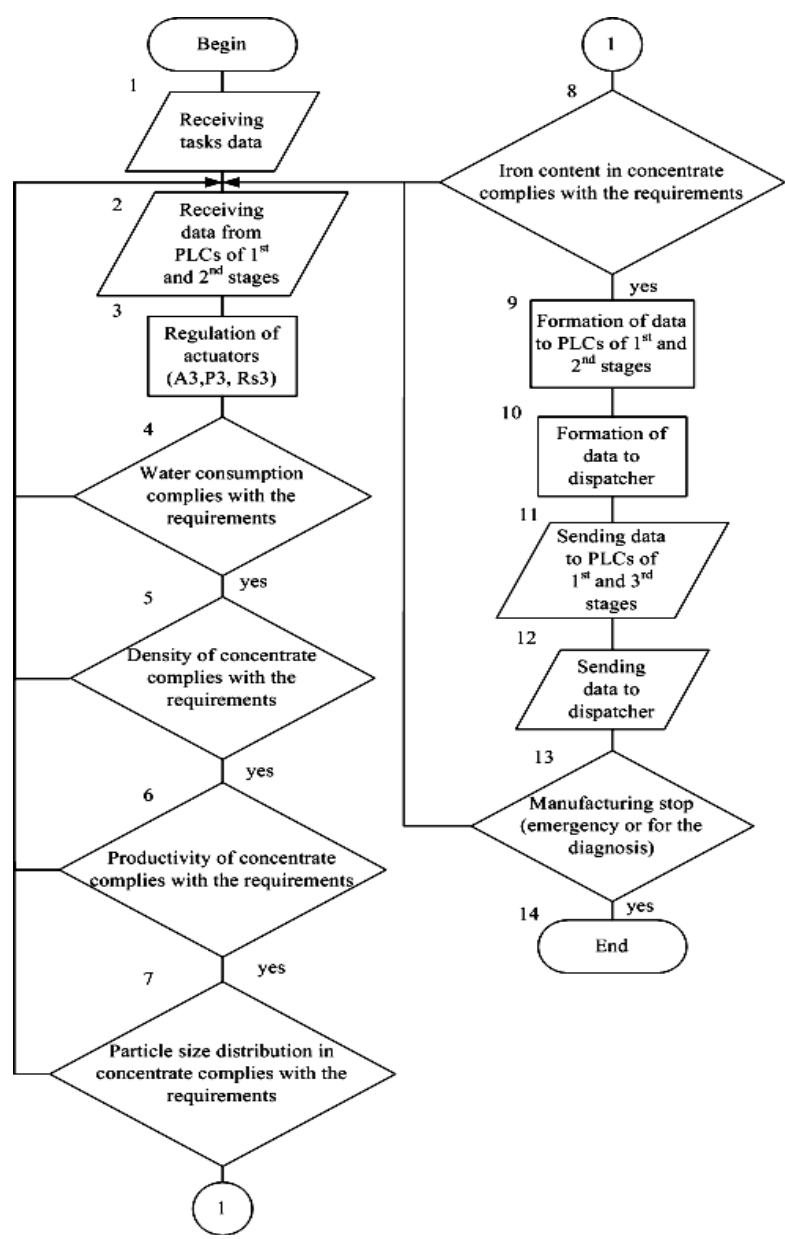

Fig. 8. The operation algorithm of PLC in the third stage of iron ore enrichment 

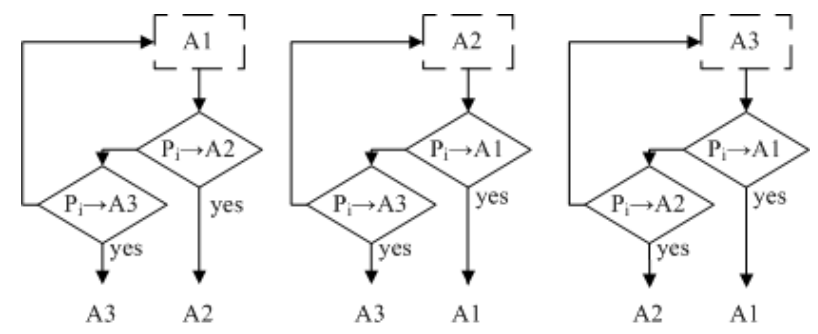

Fig. 9. Parallel functioning of algorithms

For example, if a hydrocyclone's pump motor is operating normally and produces enough power for optimum operation of the hydrocyclone, but underflow and overflow productivities and/or densities do not meet the requirements, this indicates the engine malfunction and incorrect readings of the frequency converter. If during normal operation of the engine only a part of sensors shows unsatisfactory results contradicting the results of other sensors, it indicates sensors malfunction.

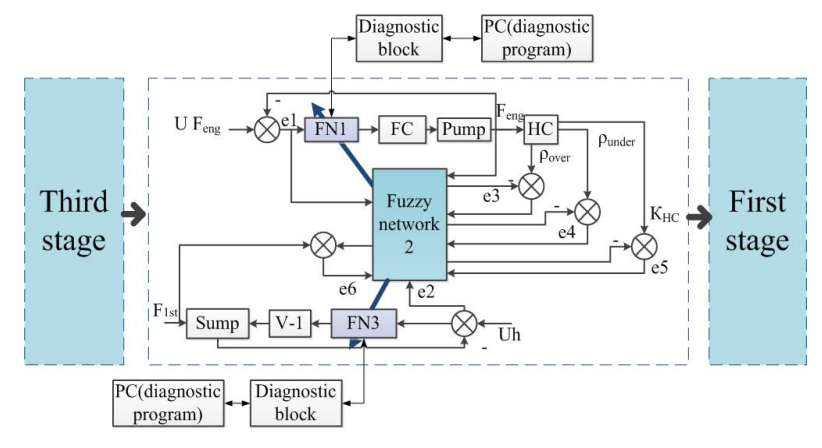

Fig. 10. Algorithmic self-diagnosed control system of hydrocyclone with connection to agent of stage with uncertain parameters

Fig. 10 contains the following notations: FC frequency converter engine; $\mathrm{P}-$ pump; $\mathrm{HC}-$ hydrocyclone; FN - fuzzy network; V-1 - the valve.

The circuit in Fig. 10 uses the feedback controllers made on fuzzy networks FN1 and FN3 that are studying through identifier FN2. Learning through identification, rather than directly on the object, it is necessary "not to interfere" with the functionality of the object influence's trials, used for training [13-16]. The disadvantages of the scheme include high demands on computing resources.
FN1 based on the error signal e1 obtained from the difference between setting signal $U F_{\text {eng. And signal of }}$ engine $\mathrm{F}_{\text {eng. }}$, produces control action on the FC. Setting signal of pulp level in sump Uh, together with the actually received signal $\mathrm{h}$ give an error e 2 arriving at FN3, which controls valve V-1 and, therefore, controls the supply of technological water in the sump. The level of pulp in the sump is also regulated in accordance with the productivity of the previous first stage $\mathrm{F}_{1 \mathrm{st}}$. Difference errors e3, e4 and e5 derived as the differences between set impacts and parameters of densities of underflow and overflow ( $\rho_{\text {uf }}$ and $\rho_{\mathrm{of}}$ ) measured at the hydrocyclone output and the ratio of productivity of underflow and overflow $\left(\mathrm{K}_{\mathrm{HC}}\right)$ also arriving at FN2 likewise in the above described e1, e2 and e6. Based on the error signal FN2 teaches FN1 and FN3 and sends a signal to FN of first stage (Fig. 2 thick lines). The control scheme of the second stage enrichment hydrocyclone can increase the efficiency of separation, by increasing the density of its output owing to the regulation of feed rate of the input material to the hydrocyclone while maintaining a constant level of pulp in the sump of hydrocyclone. Due to fluctuations in the characteristics of the incoming flow of pulp the most appropriate control system is a system of fuzzy algorithm.

Information about the state of the sensors and actuators is contained in fuzzy networks 1 and 3. As shown in Fig. 10, the information is read by a diagnostic block. The figure shows two diagnostic blocks, but they form one diagnostic circuit which communicates with the diagnostic program on the host PC. Thus, the PC fulfils two programs - control and diagnostics of the equipments condition.

The rule base in fuzzy network 2 contains the rules written on the principle shown in Table. Focusing on the criterion (2) based on measured values of productivity and density of overflow, control actions and the degree of their implementation are selected. In table $1 \mathrm{Q}, \mathrm{Q}_{\mathrm{p}}$-are measured and preset value of overflow productivity; $\rho, \rho_{p}-$ are measured and preset value of overflow density.

As a single agent second stage is interconnected with the neighboring agents - the first and third stages of iron ore enrichment. The second stage receives orders for the production of certain product quantity and specified quality from next, third stage. While, in turn, the second stage sends a similar signal to the requirements prior to the first stage.

Fragment of rule base in fuzzy network 2

\begin{tabular}{|c|c|c|c|}
\hline № & Name & Description & Action \\
\hline 1 & \multirow{9}{*}{$\begin{array}{l}\text { Measuring the density of } \\
\text { overflow, compared with } \\
\text { a setted value of density; } \\
\text { Measuring productivity } \\
\text { drain and comparison } \\
\text { with the given capacity }\end{array}$} & $\rho<\rho_{p} ; Q<Q_{p}$ & Reduce the supply of water and increase the speed of rotation of the pump's drive \\
\hline 2 & & $\rho<\rho_{p} ; Q=Q_{p}$ & Reduce the supply of water \\
\hline 3 & & $\rho<\rho_{p} ; Q>Q_{p}$ & Reduce the supply of water and reduce the speed of rotation of the pump's drive \\
\hline 4 & & $\rho=\rho_{p} ; Q<Q_{p}$ & Increase the speed of rotation of the pump's drive \\
\hline 5 & & $\rho=\rho_{p} ; Q=Q_{p}$ & No actions \\
\hline 6 & & $\rho=\rho_{p} ; Q>Q_{p}$ & Reduce the speed of rotation of the pump's drive \\
\hline 7 & & $\rho>\rho_{p} ; Q<Q_{p}$ & Increase the supply of water and reduce the speed of rotation of the pump's drive \\
\hline 8 & & $\rho>\rho_{p} ; Q=Q_{p}$ & Increase the supply of water \\
\hline 9 & & $\rho>\rho_{p} ; Q>Q_{p}$ & Increase the supply of water and reduce the speed of rotation of the pump's drive \\
\hline
\end{tabular}




\section{CONCLUSIONS}

Multiagent control enables to take into account the following - third enriching stage requirements for the quality and size of the separated product, and to regulate the process of separating pulp in hydrocyclone accordingly and, alongside to set their own requirements for the product from the previous stage, the first one. When extreme values of the second stage controlled parameters are reached, a correction signal on pulp parameters is produced, which is supplied from the first stage of enrichment. Multiagent control enables to do it without interfering with the normal operation of the system and ensures the autonomy of each control system of enrichment complex mechanisms.

Future research prospects are to improve relations with the mechanisms of the previous and subsequent agents and to develop algorithms of agents of all sections and enrichment complex overall [0].

\section{REFERENCES}

[1] Bogdanov O. S. Spravochnik po obogascheniyu rud. Tom 4. Obogatitelnyie fabriki / Pod red. O. S. Bogdanova, 2-e izd., pererab I dop. - M.: Nedra, 1984. - 360 p.

[2] Klyishinskiy E. S. Agentnyie sistemyi: klassifikatsiya I primenenie [Tekst] / E. S. Klyishinskiy // SAPR I grafika, No. 8. - 1999. - P. 90-96.

[3] Han A. G. Avtomatizatsiya obogatitelnyih fabrik / A. G. Han, V. P. Kartushin, L. V. Soroker, D. A. Skripchak. - M.: Nedra, 1974. - 280 p.

[4] Morkun V. Optimization of the second and third stages of grinding based on fuzzy control algorithms / V. Morkun, O. Savytskyi, M. Tymoshenko. // Metallurgical and Mining Industry. - 2015. - No. 8. - P. 22-25.

[5] Povarov A. I. Gidrotsiklonyi na obogatitelnyih fabrikah. - M.: "Nedra", 1978, 232 p.

[6] Yefimenko L., Tykhanskyi M. Information systems in the technological processes automatic control development by technical condition criterion. Metallurgical and Mining Industry, 2015, No. 1, P. 28-31.

[7] Bass L. Contribution to the theory of grinding processes / L. Bass, Z. Angew / Math. Phys. - 1954 - No. 5. - P. 283-292.

[8] Ragot J. Transient study of a closed grinding circuit / [Ragot J., Roesch M., Degoul P., Berube Y.] - 2-nd IFAC Symp. "Automat. Mining, Miner. And Metal. Proc.”- Pretoria. - 1977. - P. 129-142.

[9] Gurocak H. B. Fuzzy rule base optimization of a compliant wrist sensor for robotics // J. Robotic Systems. 1996, No. 13, P. 475-487.

[10] Wang L.-X. Stable adaptive fuzzy control of nonlinear systems // IEEE Trans. Fuzzy Systems 1993. No. 1 (2). P 146-155.

[11] Spooner J.T., Passino K.M. Stable adaptive control using fuzzy systems and neural networks // IEEE Trans. Fuzzy Systems. 1996. No. 4 (3). P. 339-359.

[12] Schubert. H. Aufbereitung fester mineralischer Rohstoffe. Leipzig, 1967, Bd. 11, p. 472.

[13] Sbarbaro D. Advanced control and supervision of mineral processing plants / D. Sbarbaro, R. del Villar., 2010. - 311 p.

[14] Mezentsev K.N. Raschet Multiagentnoe modelirovanie v srede NetLogo / K.N. Mezentsev //Avtomatizatsiya I upravlenie v tehnicheskih sistemah (AUTS). - 2015. - \#1. - P. 10-20.

[15] Bezgubova Yu. O. Multiagentnoe upravlenie raspredelennyimi informatsionnyimi potokami / Yu. O. Bezgubova // Obrazovatelnyie resursyi I tehnologi. - 2015. - No. 9. - P. 113-119.

[16] Uskov A. A. Printsipyi postroeniya sistem upravleniya $s$ nechetkoy logikoy // Priboryi I sistemyi. Upravlenie, Kontrol, Diagnostika. 2004. No. 6. P. 7-13.

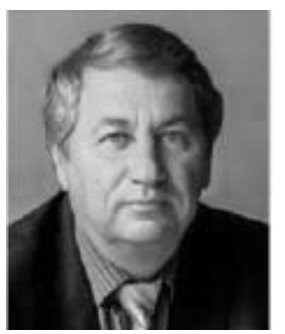

Volodymyr Morkun was born in 1951 in Moscow, Russia. He graduated from Kryvyi Rig Mining Institute with a degree in electrification and automation of mining operations in 1973 and in 1979 specialized faculty of the Moscow Institute of Steel and Alloys, specialty "Ultrasonic technique and technology". In
1977-1981 he did postgraduate degree. He received $\mathrm{Ph}$. D. in "Automatic control and regulation, process control" in 1984 and became Doctor of Engineering in "Automation of control processes" in 2000.

$\mathrm{He}$ is an academician of the Academy of Mining Sciences of Ukraine, corresponding member of the International Academy of Computer Science and Systems. He takes an active part in the organization of international scientific conferences and seminars on information processing, automation of production processes and operational quality control of mineral. He is the author of more than 200 articles. He is Chairman of the Specialized Scientific Council, a member of the Scientific Council of the Ministry of Education and Science for the professional direction of "Technology of production and processing of minerals," Provost foe Research, a member of the Academic Council and Attestation Commission of the teaching staff in Kryvyi Rig National University, Ukraine.

Mr. V. Morkun is laureate of the State Prize of Ukraine in Science and Technology (2006) for his work "The complex resource- and energy-saving geotechnology of mining and processing of minerals with control system and optimization of mining production". He was also awarded the sign "Excellence in Education of Ukraine", diploma of Ministry of Education and Science of Ukraine, the sign "Inventor of the USSR" gold medal of All-Russian Exhibition Centre USSR and first degree diploma of All-Russian Exhibition Centre USSR.

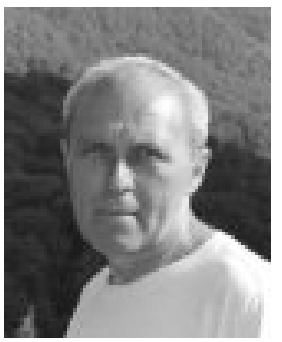

Oleksandr Savytskyi was born in Kryvyi Rih, Ukraine, in 1950. He received an engineering degree in the specialty electric drive and automation of technological processes in the Kryvyi Rih Mining Institute, Kryvyi Rih, Ukraine, in 1976 and Ph.D. degree in automation of control processes from Kryvyi Rih National University in 2000.

From 1979 to 1994 he worked as a Senior Researcher of Kryvyi Rih Mining Institute and together with state project institute: "Elektrotyazhhimproekt" (Dneropetrovsk), NKMZ (Kramatorsk) participated in projects of conveyor transport automation. From 1997 to 2013, together with the project institute "Mechanobrchermet" he participated in many projects of the electrical equipment design and automation of mining and processing enterprises. He is the author of more than 60 articles and 10 patents. His research interests include information technology, computer integrated automation system of distributed processing systems, computing and programming PLCs and PCs.

Mr. O. Savytskyi is responsible for academic courses: "Industrial Controllers and Networks", "Industrial Controls and Systems", "Programming of Industrial Controllers", "Automation of Production processes" and "Mechatronics".

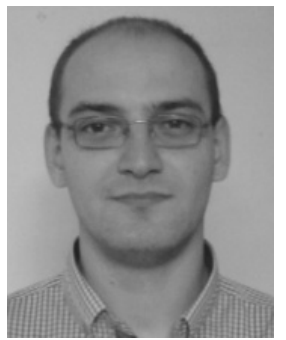

Maxym Tymoshenko was born in Kryvyi Rig, Ukraine, in 1993. He received BS and MS degrees in systems of control and automation from Kryvyi Rih Technical degree in "Automation of control processes". He is the author of 9 articles. His research interests include automated control, PLC programming, modeling of processes and systems, means of fuzzy logic, artificial intelligence, genetic algorithms, hybrid systems.

Mr. M. Tymoshenko was semi-finalist of the international contest "Go Green in the City" held by the company Schneider Electric in 2014. He also won prizes at various Hackathons. 